\title{
Fatigue Design Space for Porous Titanium Alloy Femoral Stems: Computational Approach
}

\author{
Faris Tarlochan ${ }^{1, a}$ and Hassan Mehboob ${ }^{1}$ \\ ${ }^{1}$ Mechanical and Industrial Engineering, Qatar University, Doha, Qatar
}

\begin{abstract}
The objective of this study is to develop a design space for selecting porous titanium alloy femoral stems with different stiffnesses for fatigue applications. Finite element models of stems incorporating porous structure are constructed to provide different stem stiffness. The effective material properties obtained from compression tests of these porous structures are used to model simplified femoral solid stems with porosities of ranging from $20-90 \%$. By using appreciate fatigue failure criterion, a fatigue design space is determined with factor of safety $\mathrm{Nf}>1.1$. The developed design space provides designers means to design safe porous stems.
\end{abstract}

\section{Introduction}

Total hip replacement (THR) by using metallic hip stems is a common procedure to repair damaged femurs [1]. Titanium alloys medical grade is proven to have excellent biocompatibility properties due to its excellent mechanical and biological properties [2-4]. Dense titanium stems exhibit stiffness which is approximately 6-7 times to that of the femur bone. Because of this mismatch in stiffness, cementless dense titanium stem causes aseptic loosening primarily due to stress shielding.

In order to overcome this, many researchers have investigated different designs by finite element approach. These computational models have been successfully used to investigate the biomechanical responses due to external stimuli of tissues and implants [5-13]. Some studies have focused on modifying the hip stems using various materials and designs [4, 14, 15]. Furthermore, carbon-fiber-reinforced polyetheretherketone (CFRPEEK) composites, porous biomaterials, and new designs of stems have been recently proposed to overcome the aforementioned complications [16-20]. Some other researchers focused on introducing various geometrical profiles and functionally graded materials [21-23]. Nonstochastic cellular structures were also examined however limited to small samples that are used for bone grafting and repairing the segmental bone defects, among others. Recently, a few studies focused on designing porous and semi porous hip stems to repair the damaged femur $[2,4$, 20, 24-28]. Different types of cellular structures including the cubic, diamond, and body-centered-cubic (BCC) types were used to test the mechanical properties of microstructures. These studies reveal that the fatigue limit of porous cellular microstructures corresponded to 20 $30 \%$ of the yield strength of porous cellular microstructure, which is extremely low when compared

\footnotetext{
${ }^{\mathrm{a}}$ Corresponding author: faris.tarlochan@qu.edu.qa
}

to that of dense Ti [29-33]. Therefore, the fatigue limit of porous cellular microstructures is extremely important while designing porous or semi porous stems. A challenging task involves reducing the stiffness of the porous stem while simultaneously achieving a good fatigue limit $\left(>5 \times 10^{6}\right.$ cycles). Thus, the aim of this study is to develop a design space for porous stems with different stiffness values to survive under a fatigue load (see Figure. 1). The stems were modelled according to the ISO 7206-4 standard, and loads and boundary conditions were applied.

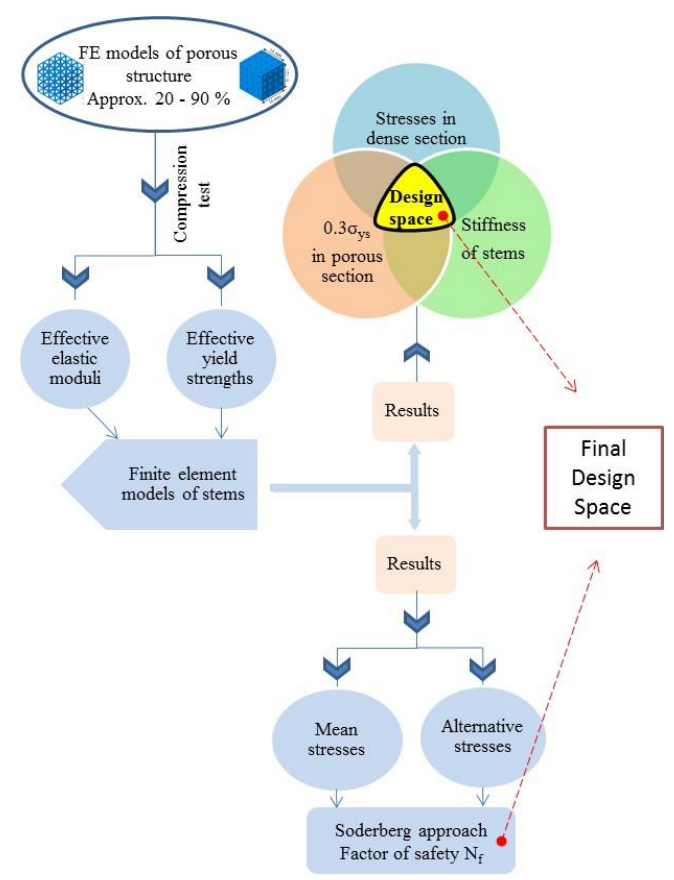

Figure 1. Analysis steps to determine the design space and factor of safety 


\section{Finite element model}

As shown in Figure 1, the finite element (FE) analysis consists of two parts: (1) to determine the effective stiffness and yield strength of different porosities of a representative volume, (2) to determine fatigue performance of these porous stems. For the first part, a 3D finite element models of porous microstructure consisting of struts arranged in a periodical manner was constructed using a commercially available finite element code, ABAQUS 6.17. Porosities of approximately $20-$ $90 \%$ was achieved by varying the strut thickness as depicted in Table 1. This porous structure is modelled as cubes with dimensions of $16 \times 16 \times 16 \mathrm{~mm}^{3}$ as shown in Figure 2. Mesh size of $0.2 \mathrm{~mm}$ is used to generate C3D10 tetrahedral elements. The sensitivity of the mesh size was obtained in a previous study [23], and a size of $0.2 \mathrm{~mm}$ was observed to be optimal. The total displacement is applied in 10 increments with an increment size of 0.1 to yield elastic and plastic regions of the stress-strain curves. Table 1 also depicts the effective stiffness and yield strength obtained from the analysis. Mechanical properties of titanium alloy used is shown in the appendix of this paper.

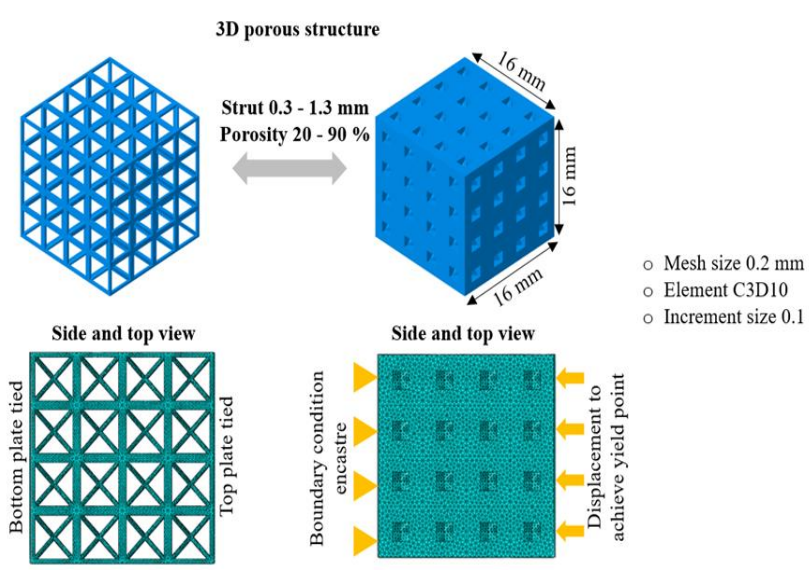

Figure 2. Finite element analysis of porous structures: details of porosity, loading and boundary conditions to obtain effective stiffness and effective yield strength.

Table 1. Approximate properties of porous microstructure.

\begin{tabular}{ccccc}
\hline $\begin{array}{c}\text { Strut thickness } \\
(\mathrm{mm})\end{array}$ & Porosity $(\%)$ & $\begin{array}{c}\text { Effective elastic } \\
\text { modulus }(\mathrm{GPa})\end{array}$ & $\begin{array}{c}\text { Effective vield } \\
\text { strength, } \sigma_{\mathrm{w3}}(\mathrm{NPa})\end{array}$ & $0.3 \mathrm{G}_{\mathrm{jy}}(\mathrm{MPa})$ \\
\hline 0.3 & 90 & 4 & 40 & 10 \\
\hline 0.5 & 70 & 9 & 90 & 30 \\
\hline 0.7 & 60 & 18 & 180 & 50 \\
\hline 0.9 & 50 & 32 & 300 & 90 \\
\hline 1.0 & 30 & 54 & 530 & 160 \\
\hline 1.3 & 20 & 77 & 760 & 230 \\
\hline
\end{tabular}

The second part of the FE analysis conducted was on the porous stems with physiological cyclic loads, and thus the ISO 7206-4 standard was followed to test the fatigue limit of the stems as shown in Figure 3. The stems are inserted in epoxy $(3.7 \mathrm{GPa})$ with orientations of $10^{\circ}$ in the ventral plane and $9^{\circ}$ in the lateral plane according to ISO 7206-4. The distance from the head of the stem to the surface of the epoxy is fixed at $80 \mathrm{~mm}$. Normal body weight of a patient is assumed as $800 \mathrm{~N}$ although the contact forces on hip joint react with approximately 250 $300 \%$ of the body weight $[34,35]$. Therefore, a load of $2.3 \mathrm{kN}$ is used axially on the head of the stem (ISO 72064) in 10 increments. The minimum load is set to $230 \mathrm{~N}$ to use the stress ratio of $\mathrm{R}=0.1$ during the fatigue test.

Additionally, $\sigma_{\min }$ and $\sigma_{\max }$ are computed as $230 \mathrm{~N}$ and $2.3 \mathrm{kN}$, respectively. The epoxy is fixed in all directions. A mesh size of $1 \mathrm{~mm}$ was used to generate C3D10 tetrahedral elements in the stem and epoxy. Furthermore, around 75,000 elements were used to mesh the stem, and approximately 190,000 elements were used to mesh the epoxy. The tie condition was used between the stem and epoxy. A rigid body plate was tied with the stem head to apply the load and to avoid any stress concentration.

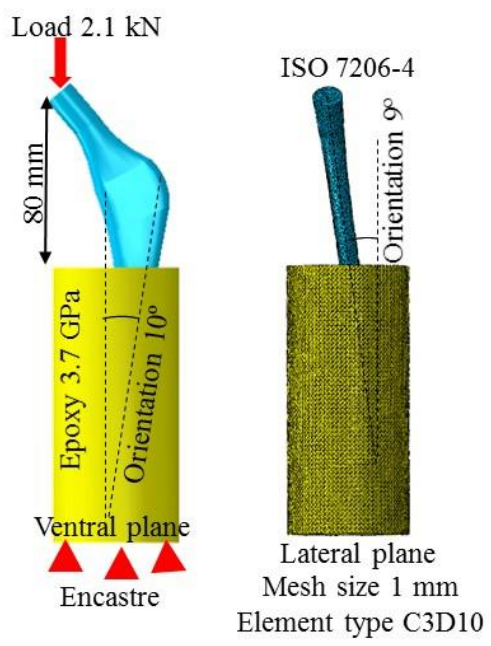

Figure 3. Detail of finite element models of femoral stems testing method of femoral stem according to ISO 7206-4 standard

Stiffness of the stem is a function of effective elastic moduli and outer dense shell thickness. A stem should satisfy the fatigue limit ( 5 million cycles) when tested according to the ISO 7206-4 standard. Therefore, a design space is determined by considering multiple criteria that include the stiffness of the stem within the range of the stiffness of bones. It should be noted here that the stresses in that porous titanium structures fatigue limit is typically in the range of $0.2-0.3 \sigma_{\mathrm{ys}}$ of the bulk titanium [29, 30, 36, 37]). Overlapping these spaces determines the design space of the porous stems that is safe under the fatigue load. Factor of safety of porous stems is also calculated using the Soderberg theory [33]. The approach is efficient in terms of estimating the stem fatigue limit under high cyclic loads. The Soberberg approach consists of mean $\left(\sigma_{\mathrm{m}}\right)$ and alternating $\left(\sigma_{\mathrm{a}}\right)$ stresses generated in the porous stems.

\section{Results and discussion}

Different porosities are tested under uniaxial compression to compute the effective mechanical properties, which in return was used for modeling the porous stems. An initial 
design space envelope as a function of $0.3 \sigma_{\mathrm{ys}}$ was developed as a function different porous structures with porosities ranging from $20-90 \%$. For the design space, the stiffness, stresses in the porous section, and stresses in the dense section are calculated to map the design space for porous stems as shown in Figure 4. The yellow regime demonstrates the accepted range of stiffness of proximal femur $(\mathrm{N} / \mathrm{mm})$. The green space shows endurance limit of $3 \mathrm{D}$ printed $\mathrm{Ti}(<500 \mathrm{MPa})$. The grey coloured area is where the stress is less than 0.3 of the yield strength of the porous structure. The design space allows freedom to design stems with different stiffness values and porosities without failure under the fatigue loads as shown in Figure 4. The black colour dotted lined area denotes a safe design space that can last for a minimum of 5 million cycles under physiological loads. Different combinations of dense shell thickness and effective elastic modulus are selected within the area to achieve the desired stiffness of the stem. Different stiffness values of the stems can be selected by a surgeon based on a patient's age, sex, bone quality, and trauma.

The next results will show the final design space by incorporating the fatigue analysis (Soderberg approach).

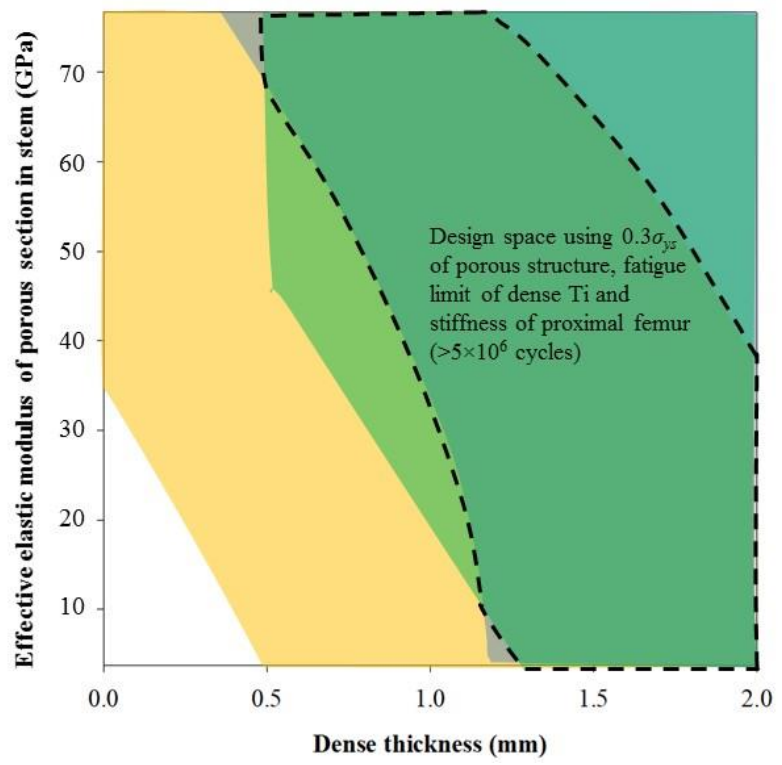

Figure 4. Design space determined using stiffness, stresses in porous section and stresses in dense section

Maximum and minimum von Mises stresses are obtained via finite element analyses when an alternating load in the range of $230-2300 \mathrm{~N}$ is applied to the stem. Stresses in porous (inner core) and solid section (outer dense shell) are computed as shown in Figure 5. In this figure, a porosity of approximate $60 \%$ with different thicknesses of the outer dense shells is illustrated to visualize stresses in the porous and dense parts of the stems. When the thickness of the dense shell increases, the stresses in the solid and porous section decrease due to increases in the stiffness. Alternative and mean stresses are calculated for porous and dense parts of the stem.

A factor of safety is calculated for the solid and porous parts of stems with different effective elastic moduli. It is observed that almost all the cases exhibited a factor of safety exceeding one, hence most porous sections with outer dense shells with thickness values of
1.5 and $2 \mathrm{~mm}$ survive under the fatigue load. We combine all the possible stems that can survive the fatigue loads with dense shell and porous sections by considering $\mathrm{Nf}>1.1$ and plot the same in Figure 6 where the blue coloured area denotes the design space with the safety factor and the grey coloured space is calculated using the yield strength of the porous structures. Figure 6 depicts this final design space.

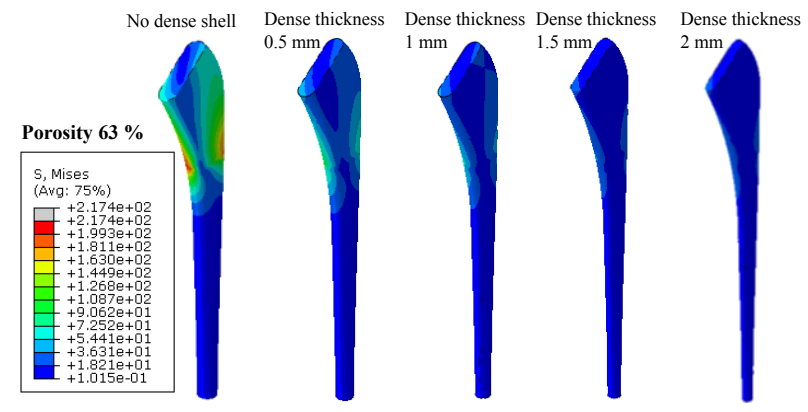

Figure 5. Stresses (MPa) in porous section of stem with different outer shell thickness

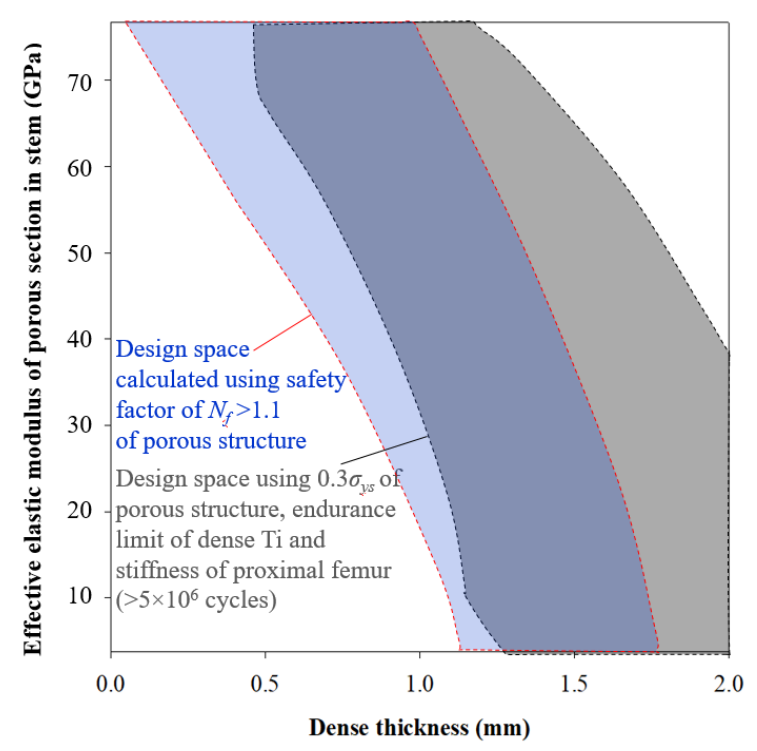

Figure 6. Design spaces calculated using Soderberg approach for safety factor of $\mathrm{Nf}>1.1$ and, stiffness, stresses in porous section and stresses in dense section

\section{Conclusion}

The aim of this study was to design cementless stems by considering fatigue limit. In the present study, finite element models of porous microstructures with porosities of $20-90 \%$ were constructed. The porous structures were subjected to uniaxial compressive loads to compute their mechanical properties. The stems were subjected to loads, boundary conditions, and orientations according to the ISO 7206-4 standard to estimate the stiffness, design space, and endurance limit. The following conclusions were obtained from this study:

- Additionally, $0.3 \sigma_{\mathrm{ys}}$ corresponded to a reasonable criterion to design a porous structure under fatigue loads when a stress ratio of 0.1 is used. 
- $\quad$ Effective mechanical properties of porous structures can be efficiently used to model the porous stems with different porosities in the range of $20-90 \%$.

- The design space was successfully determined using the stiffnesses of the stems matching those of the bone, stresses in the porous sections of the stems, and stresses in the outer dense shells.

- A factor of safety was determined using the Soderberg approach to estimate the design space for porous stem that is only dependent on the fatigue limit.

\section{Acknowledgement}

This paper was made possible by NPRP grant\# NPRP 8876-2-375 from the Qatar National Research Fund (a member of Qatar Foundation). The findings achieved herein are solely the responsibility of the authors.

\section{References}

1. Kurtz S, Ong K, Lau E, Mowat F, Halpern M. Projections of primary and revision hip and knee arthroplasty in the United States from 2005 to 2030. J Bone Joint Surg Am. 2007;89:780-5.

2. Jetté B, Brailovski V, Simoneau C, Dumas M, Terriault P. Development and in vitro validation of a simplified numerical model for the design of a biomimetic femoral stem. J Mech Behav Biomed. 2018;77:539-50.

3. Simoneau C, Terriault P, Jette B, Dumas M, Brailovski V. Development of a porous metallic femoral stem: Design, manufacturing, simulation and mechanical testing. Mater Design. 2017;114:546-56.

4. Arabnejad S, Johnston B, Tanzer M, Pasini D. Fully porous $3 \mathrm{D}$ printed titanium femoral stem to reduce stress-shielding following total hip arthroplasty. J Orthop Res. 2016.

5. Oshkour AA, Talebi H, Seyed Shirazi SF, Yau YH, Tarlochan F, Abu Osman NA. Effect of geometrical parameters on the performance of longitudinal functionally graded femoral prostheses. Artif Organs. 2015;39:156-64.

6. Stickler Y, Martinek J, Hofer C, Rattay F. A finite element model of the electrically stimulated human thigh: changes due to denervation and training. Artif Organs. 2008;32:620-4.

7. Ishida $T$, Nishimura I, Tanino $H$, Higa $M$, Ito $H$, Mitamura Y. Use of a Genetic Algorithm for Multiobjective Design Optimization of the Femoral Stem of a Cemented Total Hip Arthroplasty. Artificial Organs. 2011;35:404-10.

8. Baharuddin MY, Salleh S-H, Suhasril AA, Zulkifly AH, Lee MH, Omar MA, et al. Fabrication of LowCost, Cementless Femoral Stem 316L Stainless Steel Using Investment Casting Technique. Artificial Organs. 2014;38:603-8.

9. Sivarasu S, Beulah P, Mathew L. Novel Approach for Designing a Low Weight Hip Implant Used in
Total Hip Arthroplasty Adopting Skeletal Design Techniques. Artificial Organs. 2011;35:663-6.

10. Oki H, Ando M, Omori H, Okumura Y, Negoro K, Uchida K, et al. Relation Between Vertical Orientation and Stability of Acetabular Component in the Dysplastic Hip Simulated by Nonlinear Threedimensional Finite Element Method. Artificial Organs. 2004;28:1050-4.

11. Hashimoto N, Ando M, Yayama T, Uchida K, Kobayashi S, Negoro K, et al. Dynamic Analysis of the Resultant Force Acting on the Hip Joint During Level Walking. Artificial Organs. 2005;29:387-92.

12. Gargiulo P, Petursson T, Magnusson B, Bifulco P, Cesarelli M, Izzo GM, et al. Assessment of Total Hip Arthroplasty by Means of Computed Tomography 3D Models and Fracture Risk Evaluation. Artificial Organs. 2013;37:567-73.

13. Reggiani B, Cristofolini L, Taddei F, Viceconti M. Sensitivity of the primary stability of a cementless hip stem to its position and orientation. Artificial Organs. 2008;32:555-60.

14. Folgado J, Fernandes PR, Jacobs CR, Pellegrini VD. Influence of femoral stem geometry, material and extent of porous coating on bone ingrowth and atrophy in cementless total hip arthroplasty: an iterative finite element model. Comput Method Biomec. 2009;12:135-45.

15. Hedia HS, Shabara MAN, El-Midany TT, Fouda N. A Method of Material Optimization of Cementless Stem Through Functionally Graded Material. Int J Mech Mater Des. 2004;1:329-46.

16. Mehboob H, Chang S-H. Application of composites to orthopedic prostheses for effective bone healing: A review. Composite Structures. 2014;118:328-41.

17. Sridhar I, Adie PP, Ghista DN. Optimal design of customised hip prosthesis using fiber reinforced polymer composites. Mater Design. 2010;31:276775.

18. Rezaei F, Hassani K, Solhjoei N, Karimi A. Carbon/PEEK composite materials as an alternative for stainless steel/titanium hip prosthesis: a finite element study. Australas Phys Eng S. 2015;38:56980.

19. Oshkour AA, Abu Osman NA, Yau YH, Tarlochan F, Abas WA. Design of new generation femoral prostheses using functionally graded materials: a finite element analysis. Proc Inst Mech Eng $\mathrm{H}$. 2013;227:3-17.

20. Ramos A, Completo A, Relvas C, Simoes JA. Design process of a novel cemented hip femoral stem concept. Mater Design. 2012;33:313-21.

21. Limmahakhun S, Oloyede A, Sitthiseripratip K, Xiao Y, Yan C. 3D-printed cellular structures for bone biomimetic implants. Additive Manufacturing. 2017;15:93-101.

22. Kadirgama K, Harun WSW, Tarlochan F, Samykano M, Ramasamy D, Azir MZ, et al. Statistical and optimize of lattice structures with selective laser melting (SLM) of Ti6AL4V material. Int $\mathrm{J} \mathrm{Adv}$ Manuf Tech. 2018;97:495-510.

23. Mehboob H, Tarlochan F, Mehboob A, Chang SH. Finite element modelling and characterization of 3D 
cellular microstructures for the design of a cementless biomimetic porous hip stem. Mater Design. 2018;149:101-12.

24. Meneghini RM, Meyer C, Buckley CA, Hanssen AD, Lewallen DG. Mechanical Stability of Novel Highly Porous Metal Acetabular Components in Revision Total Hip Arthroplasty. Journal of Arthroplasty. 2010;25:337-41.

25. Mircheski I, Gradisar M. 3D finite element analysis of porous Ti-based alloy prostheses. Comput Method Biomec. 2016;19:1531-40.

26. Gonzalez FJQ, Nuno N. Finite element modelling approaches for well-ordered porous metallic materials for orthopaedic applications: cost effectiveness and geometrical considerations. Comput Method Biomec. 2016;19:845-54.

27. Jetté B, Brailovski V, Dumas M, Simoneau C, Terriault P. Femoral stem incorporating a diamond cubic lattice structure: Design, manufacture and testing. J Mech Behav Biomed. 2018;77:58-72.

28. Wang L, Kang JF, Sun CN, Li DC, Cao Y, Jin ZM. Mapping porous microstructures to yield desired mechanical properties for application in $3 \mathrm{D}$ printed bone scaffolds and orthopaedic implants. Mater Design. 2017;133:62-8.

29. Hedayati R, Hosseini-Toudeshky H, Sadighi M, Mohammadi-Aghdam $\mathrm{M}$, Zadpoor AA. Computational prediction of the fatigue behavior of additively manufactured porous metallic biomaterials. Int J Fatigue. 2016;84:67-79.

30. de Krijger J, Rans C, Van Hooreweder B, Lietaert K, Pouran B, Zadpoor AA. Effects of applied stress ratio on the fatigue behavior of additively manufactured porous biomaterials under compressive loading. J Mech Behav Biomed. 2017;70:7-16.

31. Zargarian A, Esfahanian M, Kadkhodapour J, ZiaeiRad S. Numerical simulation of the fatigue behavior of additive manufactured titanium porous lattice structures. Mat Sci Eng C-Mater. 2016;60:339-47.

32. Dumas M, Terriault P, Brailovski V. Modelling and characterization of a porosity graded lattice structure for additively manufactured biomaterials. Mater Design. 2017;121:383-92.

33. Senalp AZ, Kayabasi O, Kurtaran H. Static, dynamic and fatigue behavior of newly designed stem shapes for hip prosthesis using finite element analysis. Mater Design. 2007;28:1577-83.

34. Damm P, Kutzner I, Bergmann G, Rohlmann A, Schmidt H. Comparison of in vivo measured loads in knee, hip and spinal implants during level walking. J Biomech. 2017;51:128-32.

35. Bergmann G, Deuretzbacher G, Heller M, Graichen F, Rohlmann A, Strauss J, et al. Hip contact forces and gait patterns from routine activities. J Biomech. 2001;34:859-71.

36. Wauthle R, Ahmadi SM, Yavari SA, Mulier M, Zadpoor AA, Weinans $\mathrm{H}$, et al. Revival of pure titanium for dynamically loaded porous implants using additive manufacturing. Mat Sci Eng C-Mater. 2015;54:94-100.

37. Yavari SA, Wauthle R, van der Stok J, Riemslag AC, Janssen M, Mulier M, et al. Fatigue behavior of porous biomaterials manufactured using selective laser melting. Mat Sci Eng C-Mater. 2013;33:484958.

\section{Appendix}

\begin{tabular}{ll} 
Tensile properties \\
Yield strength & $982 \mathrm{MPa}$ \\
\hline Ultimate tensile strength & $1115 \mathrm{Mpa}$ \\
\hline
\end{tabular}

Source: International Journal of Scientific Reports (2017), Vol 3(11), pp 288-291 